\title{
EVALUACIÓN DE LA ESTABILIDAD Y ANÁLISIS DE LA CAPACIDAD DEL PROCESO DE PRODUCCIÓN DE UNA EMPRESA DE PASTAS ALIMENTICIAS
}

\section{STABILITY ASSESSMENT AND PROCESS CAPABILITY ANALYSIS IN A FOOD PASTA COMPANY}

\author{
Roxana González Álvarez \\ Facultad de Ingeniería. Universidad de Cienfuegos \\ Cienfuegos, Provincia de Cienfuegos, Cuba \\ rgonzalez@ucf.edu.cu

\section{Ana Beatriz Guerra Morffi \\ CIMEX Sucursal Cienfuegos, \\ Provincia de Cienfuegos, Cuba abgmorffi@gmail.com}

\author{
Aníbal Barrera García \\ Facultad de Ingeniería. Universidad de Cienfuegos \\ Cienfuegos, Provincia de Cienfuegos, Cuba \\ abarrera@ucf.edu.cu \\ Juan Felipe Medina Mendieta \\ Facultad de Ciencias Económicas y Empresariales, \\ Universidad de Cienfuegos \\ Cienfuegos, Provincia de Cienfuegos, Cuba \\ jfelipemm@ucf.edu.cu
}

Fecha de recepción: 29/04/2021 - Fecha de aprobación: 13/05/2021

DOI: https://doi.org/10.36995/j.visiondefuturo.2021.26.01.006.es

\section{RESUMEN}

El control estadístico de la calidad es un conjunto de herramientas y técnicas que permiten verificar, monitorear y controlar la variabilidad de los procesos, para mejorar la calidad de los productos y la competitividad empresarial. El objetivo de este estudio fue evaluar el proceso de producción de pastas largas de una empresa perteneciente al sector de la industria alimentaria, en cuanto a estabilidad y cumplimiento de especificaciones de calidad.

Se utilizó la metodología de mejora seis sigma, la que se enfoca en identificar y eliminar las causas de variación de los procesos. Para la recopilación de información se utilizaron: entrevistas, tormenta de ideas, revisión de documentos, trabajo en equipo y observación directa. Se hace uso de técnicas de documentación de procesos y de herramientas clásicas de la calidad, entre las que se encuentran: diagrama de Pareto, gráficos de control, índices de capacidad de procesos, histograma, diagrama Ishikawa y diseño experimental. También se aplicaron técnicas multivariadas de reducción de datos.

Los resultados mostraron que para la característica de calidad humedad, el proceso está fuera de control estadístico y es incapaz de cumplir con las especificaciones requeridas, para la que se investigaron las causas y se propusieron acciones de mejora, lográndose un incremento en el nivel de calidad sigma.

PALABRAS CLAVE: Pasta; Control de Calidad; Gráficos de Control; Análisis de Capacidad de Procesos; Seis Sigma.

\footnotetext{
"Visión de Futuro" Año 19, Volumen No 26 N 1, Enero - Junio 2022 - Pág 206 - 230 URL de la Revista: http://visiondefuturo.fce.unam.edu.ar/index.php/visiondefuturo/index URL del Documento: https://visiondefuturo.fce.unam.edu.ar/index.php/visiondefuturo/issue/view/22 ISSN 1668 - 8708 - Versión en Línea 


\section{ABSTRACT}

Statistical quality control is a set of tools and techniques that allows to verify, monitor and control the variability of processes to improve product quality and business competitiveness. The objective of this study was to evaluate the pasta production process of a company that belongs to the food industry sector in terms of stability and compliance of quality specifications.

The six sigma improvement methodology was used, which focuses on identifying and eliminating the causes of variation in the processes. Data collection was accomplished by the use of different techniques, such as: interviews, brainstorming, review of documents, teamwork and direct observation. In addition, process documentation techniques and classical quality tools including Pareto chart, control charts, process capability analysis, histogram, Ishikawa diagram and experimental design were used. Multivariate data reduction techniques were also applied.

The results showed for the humidity quality characteristic that the process is out of statistical control and does not have enough ability to fulfill the required specifications, for which the causes were investigated and improvement actions were proposed, achieving an increase in the sigma quality level.

KEY WORDS: Pasta; Quality Control; Control Charts; Process Capability Analysis; Six Sigma.

\section{INTRODUCCIÓN}

La pasta es un alimento con alta aceptabilidad a nivel mundial, versátil, económica, de fácil preparación y almacenamiento (Ramírez, 2015). Posee valor nutricional y sensorial (Biernacka et al., 2017), efecto de bajo índice glucémico (Makhlouf et al., 2019), bajo en sodio y grasas, sin colesterol y rico en carbohidratos complejos (Garsa, 2017). Puede combinarse con gran variedad de salsas y saborizantes (Murray, Kiszonas y Morris, 2017).

Se obtiene mediante el mezclado de agua con sémola de trigo o harina de trigo, o mezclas de ellas sometida a los procesos de amasado, prensado, moldeado y secado (NC 935: 2012). Se le pueden añadir enriquecedores o aditivos alimentarios que aumenten su valor nutricional (NC 935: 2012; Bustos, Pérez y León, 2015).

La calidad de las pastas se evalúa mediante la realización de pruebas basadas en la determinación de propiedades físico-químicas (acidez, humedad) y de cocción (Carrasquero, 2009; Biernacka et al. 2018; Peña, 2019), así como la evaluación nutricional y

\footnotetext{
“Visión de Futuro" Año 19, Volumen N²6 N 1, Enero - Junio 2022 - Pág 206 - 230 URL de la Revista: http://visiondefuturo.fce.unam.edu.ar/index.php/visiondefuturo/index URL del Documento: https://visiondefuturo.fce.unam.edu.ar/index.php/visiondefuturo/issue/view/22 ISSN 1668 - 8708 - Versión en Línea 
sensorial (textura, sabor, color, aroma) (Larrosa et al., 2016; Bouasla, Wójtowicz y Zidoune, 2017; Biernacka et al., 2017).

En el caso de las características físico-químicas, el cumplimiento de las especificaciones de calidad contribuye a disminuir los riesgos microbiológicos y mantener las propiedades sensoriales deseadas (Carrasquero, 2009; Ramírez, 2015; Peña, 2019). Por su parte, en el análisis sensorial autores como Biernacka, Dziki, Gawlik-Dziki, Różyło y Siastała (2017) explican que los parámetros de referencia se encuentran fuertemente afectados por el mercado, lo que limita la realización de estudios con un enfoque científico. Tanto el color de la pasta como la textura constituyen características de calidad que dependen en gran medida de las propiedades de la composición de la materia prima (Biernacka et al., 2017).

Es preciso destacar que la pasta de mejor calidad está hecha de sémola de trigo duro, que se comercializa a un precio superior al del trigo blando; es por ello que la pasta a menudo se produce a partir de este último (Fuad y Prabhasankar, 2010). El producto obtenido de dicha harina generalmente se caracteriza por una peor calidad de cocción (Biernacka et al., 2017), por lo que se requiere de un procesamiento adecuado y formulaciones equilibradas para contrarrestar sus pobres propiedades tecnológicas (Fuad y Prabhasankar, 2010).

Fuad y Prabhasankar (2010) y Biernacka, Dziki, Gawlik-Dziki, Różyło y Siastała (2017) indican que para obtener pastas de alta calidad es necesario seleccionar adecuadamente las materias primas, ingredientes y aditivos a utilizar, controlar las variables de entrada de la línea de producción y cumplir los requisitos de empaque establecidos que garantizan la vida útil del producto.

Por su parte Ogawa y Adachi (2017) plantean que la etapa más compleja del proceso de producción de las pastas es el secado. Algunas investigaciones han demostrado como las condiciones de temperatura y humedad de la operación de secado influyen en la calidad de la pasta (Sicignano et al., 2015; Piwińska et al., 2016). También Peña (2019) enfatiza en que un correcto secado le confiere a la pasta estabilidad, fuerza, cohesión, mejor desempeño durante la cocción, menor riesgo de crecimiento microbiológico y una vida útil prolongada.

El monitoreo y control de la calidad en la industria alimentaria requiere de la aplicación de herramientas y técnicas estadísticas que permitan verificar, monitorear y controlar la variabilidad de sus procesos productivos para mejorar la calidad, la competitividad y el desempeño empresarial (Soriano, Oprime y Lizarelli, 2017).

\footnotetext{
"Visión de Futuro" Año 19, Volumen No 26 N 1, Enero - Junio 2022 - Pág 206 - 230

URL de la Revista: http://visiondefuturo.fce.unam.edu.ar/index.php/visiondefuturo/index

URL del Documento: https://visiondefuturo.fce.unam.edu.ar/index.php/visiondefuturo/issue/view/22

ISSN 1668 - 8708 - Versión en Línea

E-mail: revistacientifica@fce.unam.edu.ar
} 
En este sector ha sido ampliamente utilizado el control estadístico de la calidad (Rábago, Padilla y Rangel, 2014; Chero et al., 2019), constituyendo una de sus funciones clave, puesto que se relaciona con la verificación de productos para cumplir con las normativas alimentarias y atraer la confianza de los consumidores.

Un estudio realizado por Abdul, Antony y Arshed, (2016) mostró que la implementación de herramientas del control estadístico de la calidad, brinda a la industria alimentaria las ventajas para mejorar el rendimiento de los procesos, como la calidad y el funcionamiento del producto. No obstante Soriano, Oprime y Lizarelli (2017) plantean que aún faltan revisiones sobre la gestión de la calidad y las prácticas de mejora en este sector, especialmente en la aplicación del control estadístico de la calidad.

Autores como Idrissi y Benazzouz (2019) sugieren que con la utilización de seis sigma (SS), se ha fomentado el uso de datos y el pensamiento estadístico, metodología que se enfoca en mejorar el nivel de desempeño y la capacidad de los procesos organizacionales mediante la reducción de la variabilidad.

También Abdul, Antony, Arshed y Albliwi (2017) y Message, Godhino y Fredendall (2018) plantean que la implementación de actividades o programas relacionados con la calidad como SS garantiza que la preparación de alimentos sea segura y de calidad y que dicha metodología es efectiva para el sector alimentario, cuya implementación está aún creciendo.

En el caso concreto de Cuba, las empresas de la industria alimentaria requieren poner el énfasis en la mejora de la calidad de sus productos y en el desempeño empresarial, que les permita sobrevivir en un entorno cada vez más competitivo. En este sentido el cumplimiento de las normas alimentarias establecidas y el control de los procesos de producción para garantizar la calidad e inocuidad de los alimentos constituyen problemáticas de actualidad e importancia estratégicas.

Unido a lo anterior, se tiene que existen carencias en la práctica cotidiana empresarial en este sector en Cuba, en cuanto al uso de técnicas y herramientas estadísticas que permitan controlar los procesos de producción, lo que afecta la calidad del producto final.

La presente investigación se realizó en una empresa de producción de pastas largas que distribuye sus productos en la red de comercio minorista del país, centros de consumo social (hospitales, escuelas) e instituciones turísticas. Durante el primer cuatrimestre del año 2019 se identificaron pérdidas por concepto de mala calidad que están en el orden de 66,60 toneladas equivalentes a 95160 pesos.

La organización tiene entre sus prioridades, fomentar el uso de herramientas y técnicas estadísticas que permitan el control de la calidad de sus producciones con un

\footnotetext{
“Visión de Futuro" Año 19, Volumen No 26 N 1, Enero - Junio 2022 - Pág 206 - 230

URL de la Revista: http://visiondefuturo.fce.unam.edu.ar/index.php/visiondefuturo/index

URL del Documento: https://visiondefuturo.fce.unam.edu.ar/index.php/visiondefuturo/issue/view/22

ISSN 1668 - 8708 - Versión en Línea

E-mail: revistacientifica@fce.unam.edu.ar
} 
enfoque de mejora continua. El objetivo del presente trabajo es evaluar la estabilidad y capacidad del proceso de producción de pastas largas. Con la realización del mismo se determinan los principales problemas relacionados con la inestabilidad y la baja capacidad del proceso para cumplir con especificaciones, así como la propuesta de acciones de mejora, que se visualizan en un incremento en el nivel de calidad sigma.

\section{DESARROLLO}

\section{Materiales y Métodos}

El procedimiento empleado para el desarrollo de la investigación es la metodología seis sigma (ver Figura №1). Este se organiza metodológicamente en cinco etapas.

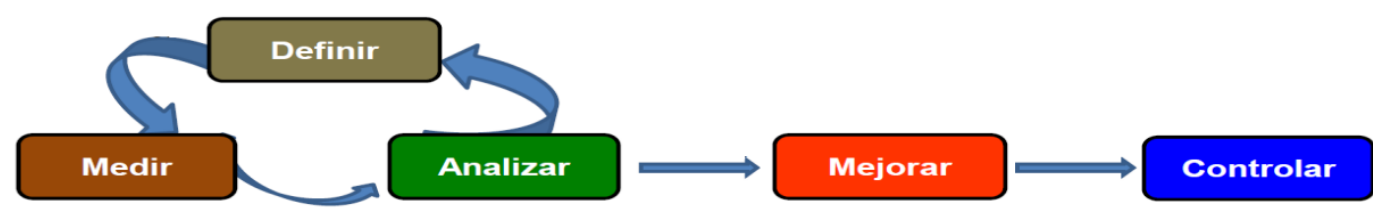

Figura No 1. Secuencia Seis Sigma DMAIC

Fuente: ISO 13053: 2011

A continuación se explican cada una de estas etapas a partir de lo expuesto por García (2014):

\section{Etapa I: Definir}

Consiste en realizar un diagnóstico de la situación actual de la empresa identificando cuáles son los elementos seleccionados para aplicar la metodología. Ello puede partir de sus objetivos estratégicos, desempeño de los procesos y los aspectos deficientes de servicio al cliente que dan respuesta a los requisitos del producto y/o servicio.

\section{Etapa II: Medir}

Se deben determinar cuáles son las características críticas que influyen sobre las variables resultantes del proceso y medirlas. Se debe preparar un plan de recolección de datos, para lo cual es importante asegurarse de la confiabilidad de los dispositivos de medición que pueden ser instrumentos de medición o cuestionarios de evaluación para el servicio.

\section{Etapa III: Analizar}

Consiste en analizar los datos obtenidos de la etapa de medición identificando las fuentes de variabilidad. En la misma se deducen las relaciones existentes entre las variables "Visión de Futuro" Año 19, Volumen $\mathbf{N}^{\circ} \mathbf{2 6} \mathbf{N}^{\circ}$ 1, Enero - Junio 2022 - Pág 206 - 230
URL de la Revista: $\underline{\text { http://visiondefuturo.fce.unam.edu.ar/index.php/visiondefuturo/index }}$
URL del Documento: $\underline{\text { https://visiondefuturo.fce.unam.edu.ar/index.php/visiondefuturo/issue/view/22 }}$
ISSN 1668 - 8708 - Versión en Línea
E-mail: revistacientifica@fce.unam.edu.ar 
de entrada y salida del proceso. Esta etapa es la de mayor contenido técnico ya que se comprueba las teorías o hipótesis sobre el funcionamiento del proceso, donde es necesario acudir a herramientas estadísticas avanzadas. Como salidas de esta etapa se tiene el análisis de la influencia de estas variables, capacidad de procesos, identificación de las fuentes de variabilidad y preparación de la etapa de mejora a partir de las causas raíces.

\section{Etapa IV: Mejorar}

Comienza una vez que se han identificado las citadas causas vitales. Se desarrolla un plan de implantación de mejoras que aporte soluciones sólidas para eliminar los defectos en los que incurre el proceso y se realiza un análisis costo- beneficio de las soluciones, de forma que puedan ser una ayuda a la toma de decisiones de la dirección de la empresa. Generalmente, antes de ser implantadas las mejoras, es recomendable hacer una prueba piloto de las mismas para determinar su alcance.

\section{Etapa V: Controlar}

Se comprueba la validez de las soluciones propuestas y probadas en escala piloto. Se deben establecer controles, no sólo sobre las salidas del proceso sino también sobre las causas vitales que inciden en su consecución. En ocasiones los procesos, pasado un tiempo pierden regularidad en su comportamiento, por lo que para evitarlo, la metodología seis sigma impone controles que monitorizan permanentemente los procesos con el fin de mantener las ganancias conseguidas.

\section{Resultados}

Para la aplicación se tomó como objeto de estudio una empresa de producción de pastas largas, perteneciente al sector de la industria alimentaria.

\section{Etapa I: Definir}

La empresa objeto de estudio produce tres tipos de pastas largas secas (Espaguetis). Las diferencias entre estas radican en la composición y el tipo de materia prima a utilizar. Atendiendo a la clasificación que se establece en la NC 935: 2012, las pastas alimenticias secas se clasifican en seis grados de calidad. Las que se describen a continuación corresponden a las producciones de la empresa objeto de estudio:

- Grado A: Pastas alimenticias secas elaboradas con sémola o harina granular de trigo duro.

\footnotetext{
"Visión de Futuro" Año 19, Volumen No 26 N 1, Enero - Junio 2022 - Pág 206 - 230

URL de la Revista: http://visiondefuturo.fce.unam.edu.ar/index.php/visiondefuturo/index

URL del Documento: https://visiondefuturo.fce.unam.edu.ar/index.php/visiondefuturo/issue/view/22

ISSN 1668 - 8708 - Versión en Línea

E-mail: revistacientifica@fce.unam.edu.ar
} 
- Grado B: Pastas alimenticias secas elaboradas con mezcla de sémolas y harina granular de trigo común en las proporciones $50 \%$ sémola - $50 \%$ harina y $30 \%$ sémola - $70 \%$ harina.

- Grado C: Pastas integrales con sémola y salvado con la proporción de hasta $5 \%$ de salvado.

Durante el período de enero a abril de 2019 la empresa de producción de pastas largas seleccionada produjo un total de 2308.37 toneladas. De ellas 1769,91 toneladas corresponden al espagueti de $400 \mathrm{~g}$ Grado B, lo que representa el 76,67\% del total, según se muestra en el Diagrama de Pareto de la Figura №2.

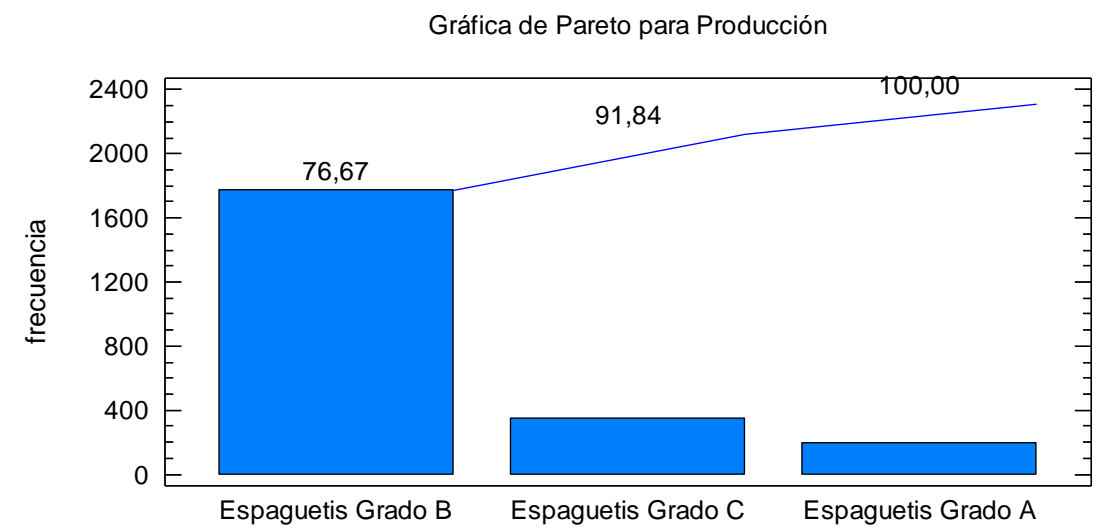

Figura No2: Diagrama de Pareto para Producción (Ton) en el período de enero - abril 2019 Fuente: Elaboración Propia

En ese mismo período se identificaron 66,60 toneladas de pérdidas asociados a la mala calidad de las pastas, equivalente a 95160 pesos. En la Figura №3 se muestran las pérdidas por tipo de producto, donde el espagueti Grado B representa el 84,94\% del total.

Gráfica de Pareto para Pérdidas

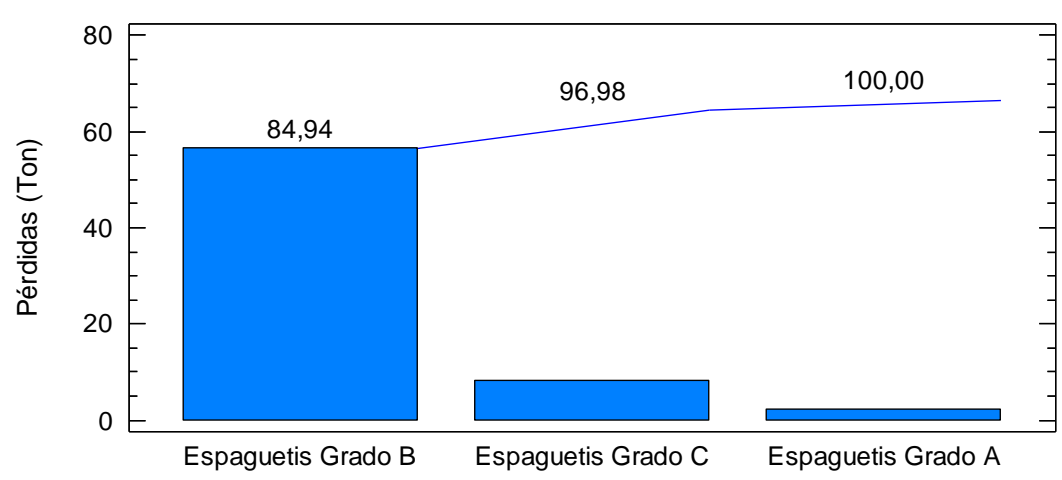

Figura N³: Diagrama de Pareto para Pérdidas (Ton) en el período de enero - abril 2019 Fuente: Elaboración Propia

A partir de la situación expuesta se hace evidente la necesidad de aplicar herramientas de control estadístico de la calidad para conocer el estado actual del proceso

\footnotetext{
"Visión de Futuro" Año 19, Volumen No 26 N 1, Enero - Junio 2022 - Pág 206 - 230

URL de la Revista: http://visiondefuturo.fce.unam.edu.ar/index.php/visiondefuturo/index

URL del Documento: https://visiondefuturo.fce.unam.edu.ar/index.php/visiondefuturo/issue/view/22

ISSN 1668 - 8708 - Versión en Línea

E-mail: revistacientifica@fce.unam.edu.ar
} 
de producción de pastas en cuanto a estabilidad y capacidad para cumplir con especificaciones.

Las características de calidad por las que un lote es aceptado así como sus especificaciones se encuentran establecidas en la Norma Ramal de la Industria Alimentaria NRIAL 168: 2001 Pastas Alimenticias - Especificaciones.

Es importante destacar que los especialistas consideran que el principal problema asociado a las pérdidas por concepto de mala calidad de las pastas se debe a incumplimiento de las características físico-químicas. La Tabla №1 muestra dichas características.

Tabla N¹: Características de calidad físico-químicas de las pastas alimenticias secas Grado B

\begin{tabular}{|c|c|}
\hline Características de calidad & Grado B \\
\hline Humedad (\%) & $\begin{array}{r}\text { Especificación Inferior (EI) }=11 \% \\
\text { Valor Nominal }(\mathrm{N})=12 \% \\
\text { Especificación Superior (ES) }=13 \%\end{array}$ \\
\hline Acidez (\%) & ES $=0.4 \%$ \\
\hline
\end{tabular}

Fuente: NRIAL 168: 2001

Un alto contenido de humedad (>13\%) potencia el riesgo de alteraciones microbiológicas del producto, ya que el mismo se hace más propenso a la descomposición y como consecuencia aparecen las toxiinfecciones, además de perder las características sensoriales deseadas. Mientras tanto una humedad muy baja $(<11 \%)$, además de alterar el proceso de cocción de la pasta implica un elevado incremento en los costos para la empresa y una disminución del rendimiento.

La acidez también garantiza la inocuidad de las pastas previniendo enfermedades. Valores de $0,4 \%$ o menores, permiten obtener un producto inocuo listo para el consumo humano.

En esta etapa también se documentó el proceso de producción de pastas mediante un diagrama SIPOC (proveedores-entradas-proceso-salidas-clientes), un diagrama de flujo básico y la ficha correspondiente, herramientas de utilidad para entender y describir dicho proceso.

\section{Etapa II: Medir}

\section{Evaluación de la estabilidad del proceso}

Para evaluar la estabilidad se utilizaron los gráficos de control, en este caso en particular se seleccionó la carta de medias para evaluar la estabilidad en cuanto a tendencia

\footnotetext{
"Visión de Futuro" Año 19, Volumen No 26 N 1, Enero - Junio 2022 - Pág 206 - 230

URL de la Revista: http://visiondefuturo.fce.unam.edu.ar/index.php/visiondefuturo/index

URL del Documento: https://visiondefuturo.fce.unam.edu.ar/index.php/visiondefuturo/issue/view/22

ISSN 1668 - 8708 - Versión en Línea

E-mail: revistacientifica@fce.unam.edu.ar
} 
central y la carta de rangos para evaluar la estabilidad de la amplitud de la variación. A tal efecto se tomaron ocho observaciones diarias de humedad y acidez durante 24 días del mes de abril de 2019.

Se seleccionaron estas cartas dado que se aplican a características de calidad de tipo continuo como lo son la humedad y la acidez, se considera como tamaño del subgrupo el total de observaciones que se realizan diariamente, siendo ocho. Este tipo de análisis permite identificar si el proceso está trabajando con causas comunes o especiales de variación.

- Característica de calidad: Humedad (\%)

Las Figuras №2 y №3 muestran las cartas de media y de rango para la humedad (\%) respectivamente correspondiente al mes de abril de 2019.

Gráfico X-bar para Humedad

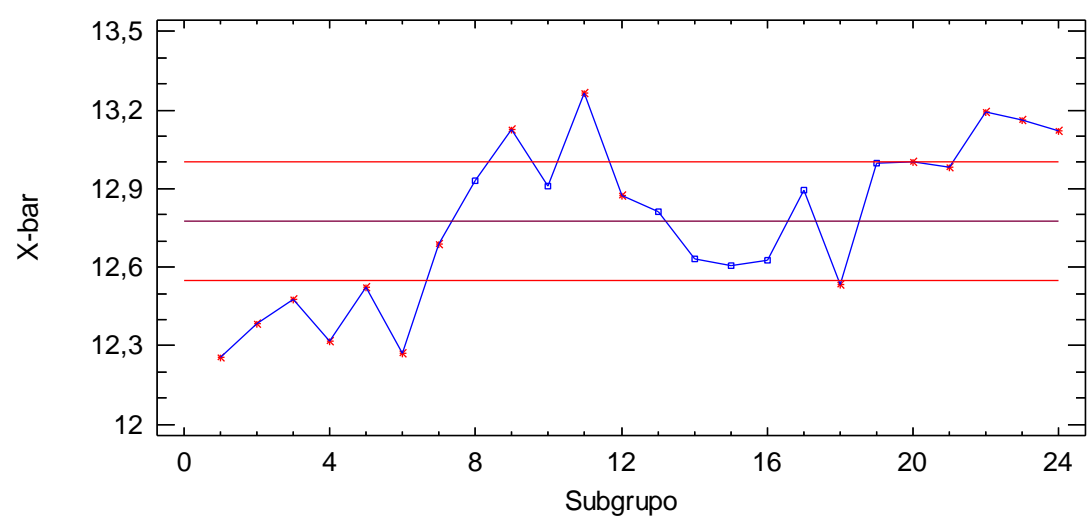

Figura N²: Gráfico de control de medias para la característica de calidad Humedad (\%) en el mes de abril de 2019

Fuente: Elaboración Propia

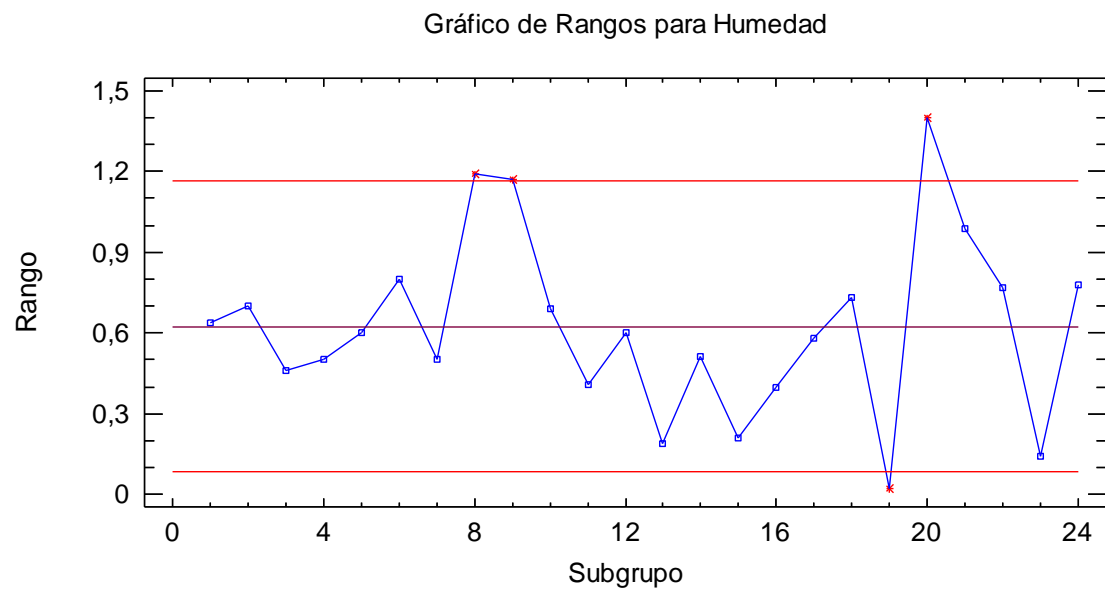

$\mathrm{LSC}=1,16$

$\mathrm{CTR}=0,62$

$\mathrm{LIC}=0,08$

Figura N³: Gráfico de control de rangos para la característica de calidad Humedad (\%) en el mes de abril de 2019

Fuente: Elaboración Propia

\footnotetext{
"Visión de Futuro" Año 19, Volumen N²6 N 1, Enero - Junio 2022 - Pág 206 - 230

URL de la Revista: http://visiondefuturo.fce.unam.edu.ar/index.php/visiondefuturo/index

URL del Documento: https://visiondefuturo.fce.unam.edu.ar/index.php/visiondefuturo/issue/view/22

ISSN 1668 - 8708 - Versión en Línea

E-mail: revistacientifica@fce.unam.edu.ar
} 
Para esta característica de calidad se tiene que el proceso se encuentra trabajando con causas especiales de variación puesto que se observan puntos fuera de los límites de control y comportamientos no aleatorios. La prueba de corridas busca e identifica cualquier patrón inusual en los datos. La Tabla №2 muestra el subgrupo en el que se detectó el patrón inusual, así como la regla particular que se ha violado. Se identificaron un total de 24 secuencias inusuales en el gráfico de medias y una en el gráfico de rangos.

Tabla N²: Prueba de corridas para para la característica de calidad Humedad (\%)

\begin{tabular}{|c|c|c|c|}
\hline \multicolumn{4}{|c|}{ Pruebas de Corridas } \\
\hline \multicolumn{3}{|c|}{ Violaciones } & Reglas \\
\hline Subgrupo & Gráfico X-bar & $\begin{array}{c}\text { Gráfico de } \\
\text { Rangos }\end{array}$ & \multirow{16}{*}{$\begin{array}{l}\text { (A) Secuencias arriba o abajo de la línea } \\
\text { central con longitud } 8 \text { o mayor. } \\
\text { (B) Secuencias arriba o abajo de longitud } 8 \\
\text { o mayor. } \\
\text { (C) Conjuntos de } 5 \text { subgrupos con al menos } \\
4 \text { más allá de } 1,0 \text { sigma. } \\
\text { (D) Conjuntos de } 3 \text { subgrupos con al menos } \\
2 \text { más allá de } 2,0 \text { sigma. } \\
\text { (E) Conjuntos de } 15 \text { subgrupos en o dentro } \\
\text { de } 1,0 \text { sigma. } \\
\text { (F) Conjuntos de } 8 \text { subgrupos más allá de } \\
2,0 \text { sigma. } \\
\text { (G) Conjuntos de } 8 \\
\text { alternando arriba y abajo. }\end{array}$} \\
\hline 2 & $\mathrm{D}$ & & \\
\hline 3 & $\mathrm{D}$ & & \\
\hline 4 & CD & & \\
\hline 5 & CD & & \\
\hline 6 & $\mathrm{CD}$ & & \\
\hline 7 & $\mathrm{C}$ & & \\
\hline 9 & $\mathrm{D}$ & $\mathrm{D}$ & \\
\hline 11 & CD & & \\
\hline 12 & $\mathrm{C}$ & & \\
\hline 18 & $\mathrm{C}$ & & \\
\hline 20 & $\mathrm{D}$ & & \\
\hline 21 & CD & & \\
\hline 22 & CD & & \\
\hline 23 & CD & & \\
\hline 24 & CD & & \\
\hline
\end{tabular}

Fuente: Elaboración Propia

En el caso del gráfico de medias se observan desplazamientos o cambios en el nivel promedio del proceso, lo que indica en este caso que el proceso ha empeorado. Esto ocurre cuando uno o más puntos se salen de los límites de control o cuando hay una tendencia larga y clara a que los puntos consecutivos caigan de un sólo lado de la línea central.

Un proceso muy inestable es un proceso con pobre estandarización, donde hay cambios continuos o mucha variación atribuible a materiales, mediciones, diferencias en la condiciones de operación de la maquinaria y desajustes, distintos criterios y falta de capacitación de los operarios, entre otras.

- Característica de calidad: Acidez (\%)

Las Figuras $N^{\circ} 4$ y No5 muestran las cartas de medias y rangos para la Acidez (\%). Para esta característica de calidad se observa que el proceso se encuentra trabajando con causas comunes de variación, puesto que sus puntos caen dentro de los límites de control y fluctúan o varían de manera aleatoria a lo ancho de la carta. Puede decirse que el proceso

\footnotetext{
“Visión de Futuro" Año 19, Volumen No 26 N 1, Enero - Junio 2022 - Pág 206 - 230

URL de la Revista: http://visiondefuturo.fce.unam.edu.ar/index.php/visiondefuturo/index

URL del Documento: https://visiondefuturo.fce.unam.edu.ar/index.php/visiondefuturo/issue/view/22

ISSN 1668 - 8708 - Versión en Línea

E-mail: revistacientifica@fce.unam.edu.ar
} 
está en un estado de control estadístico, es decir, su comportamiento es predecible en el futuro inmediato.

Gráfico X-bar para Acidez

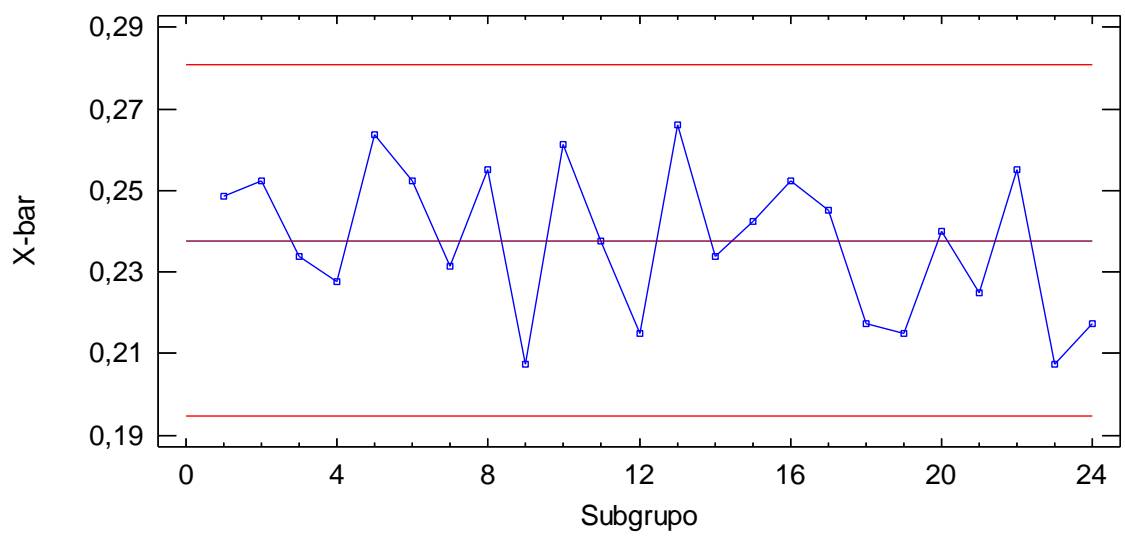

Figura N4: Gráfico de control de medias para la característica de calidad Acidez (\%) en el mes de abril de 2019

Fuente: Elaboración Propia

Gráfico de Rangos para Acidez

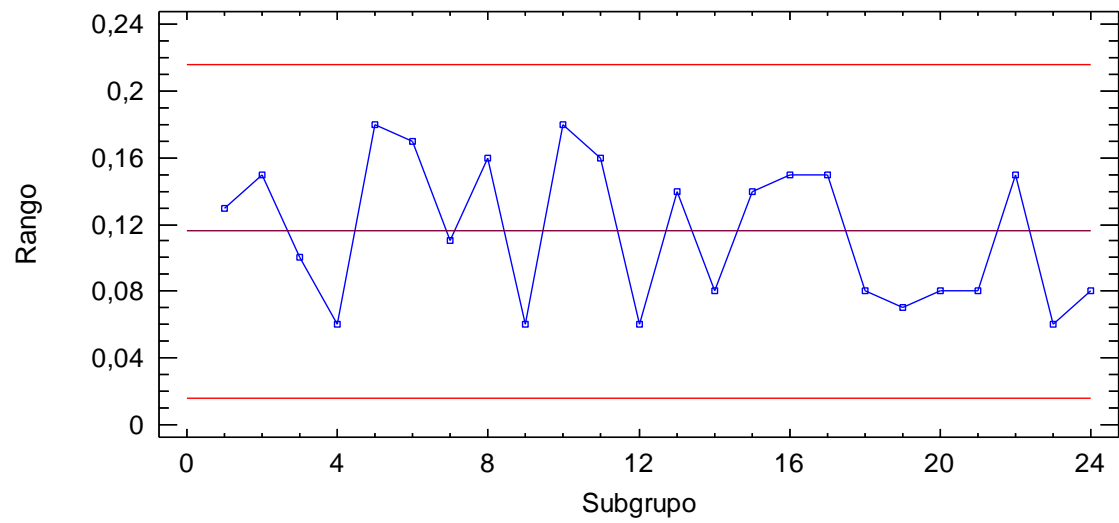

Figura N05: Gráfico de control de rangos para la característica de calidad Acidez (\%) en el mes de abril de 2019

Fuente: Elaboración Propia

\section{Evaluación de la capacidad del proceso}

La evaluación de la capacidad del proceso, es decir, de la habilidad para cumplir con las especificaciones de calidad, se evalúa a partir de los índices de capacidad para variables continuas.

- Característica de calidad: Humedad (\%)

En este caso se tiene una variable del tipo valor nominal es mejor, donde para considerar que hay calidad las mediciones deben ser iguales a cierto valor nominal o ideal $(\mathrm{N}=12 \%)$, o al menos tienen que estar con holgura dentro de las especificaciones inferior

\footnotetext{
"Visión de Futuro" Año 19, Volumen No 26 No 1, Enero - Junio 2022 - Pág 206 - 230

URL de la Revista: http://visiondefuturo.fce.unam.edu.ar/index.php/visiondefuturo/index

URL del Documento: https://visiondefuturo.fce.unam.edu.ar/index.php/visiondefuturo/issue/view/22

ISSN 1668 - 8708 - Versión en Línea

E-mail: revistacientifica@fce.unam.edu.ar
} 
$(E I=11 \%)$ y superior ( $E S=13 \%)$. Lo que se busca es ver si el proceso es capaz de cumplir con dichas especificaciones.

La Figura No6 muestra el gráfico de capacidad para la humedad y la Tabla No2 los índices de capacidad estimados de corto y largo plazos. La capacidad de corto plazo representa el potencial del proceso, es decir, lo mejor que se puede esperar del mismo. Se evidencia que el proceso es potencialmente capaz de cumplir con especificaciones si estuviera centrado (Clase 1: Adecuado para el trabajo) puesto que el valor de $\mathrm{Cp}=1,55$ es mayor que 1,33 según lo que establecen Gutiérrez y De la Vara (2013).

El análisis de los índices unilaterales permite concluir que el proceso es capaz de cumplir con la El al ser el índice Cpk (inferior) mayor que 1,25, mientras que el Çpk (superior) indica que el proceso no es capaz de cumplir con la ES según el criterio de Gutiérrez y De la Vara (2013). Además de acuerdo al índice K, el proceso está descentrado a la derecha del valor nominal en un $77 \%$, lo que influye en su baja capacidad.

El análisis realizado con los índices se corrobora al comparar los límites reales del proceso con las especificaciones en el gráfico de capacidad. Según estos análisis y de acuerdo a los resultados obtenidos, el $14,58 \%$ de los lotes no cumplen con la ES, equivalente a 145827 por cada millón producido.

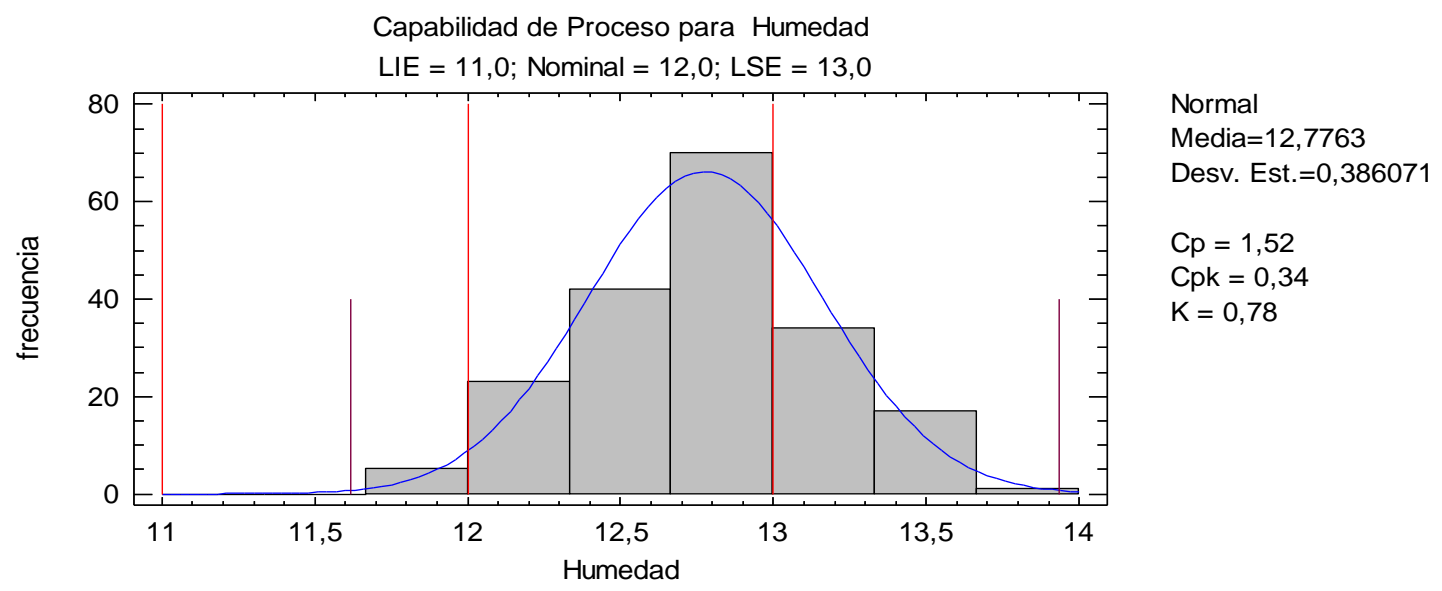

Figura № 6: Análisis de capacidad para Humedad en el mes de abril de 2019 Fuente: Elaboración Propia

\footnotetext{
"Visión de Futuro" Año 19, Volumen No 26 N 1, Enero - Junio 2022 - Pág 206 - 230

URL de la Revista: http://visiondefuturo.fce.unam.edu.ar/index.php/visiondefuturo/index

URL del Documento: https://visiondefuturo.fce.unam.edu.ar/index.php/visiondefuturo/issue/view/22

ISSN 1668 - 8708 - Versión en Línea

E-mail: revistacientifica@fce.unam.edu.ar
} 
Tabla No2: Índices de capacidad para Humedad en el mes de abril de 2019

\begin{tabular}{|c|c|c|}
\hline \multicolumn{3}{|c|}{ Especificaciones } \\
\hline LSE $=$ & Nom $=12,0$ & LIE $=11,0$ \\
\hline Índices & Capacidad Corto Plazo & Desempeño Largo Plazo \\
\hline Sigma & 0,214261 & 0,386737 \\
\hline $\mathrm{Cp} / \mathrm{Pp}$ & 1,55574 & 0,861912 \\
\hline Cpk/Ppk & 0,351499 & 0,194738 \\
\hline Cpk/Ppk (superior) & 0,351499 & 0,194738 \\
\hline Cpk/Ppk (inferior) & 2,75998 & 1,52909 \\
\hline $\mathrm{K}$ & & 0,774063 \\
\hline$\%$ fuera de especificaciones & 14,5827 & 27,9539 \\
\hline DPM & 145827, & 279539, \\
\hline Nivel de Calidad Sigma & 2,5545 & 2,08421 \\
\hline
\end{tabular}

Fuente: Elaboración Propia

Por su parte los índices $\mathrm{P}_{\mathrm{p}}$ y $\mathrm{P}_{\mathrm{pk}}$ están enfocados al desempeño del proceso a largo plazo y no sólo a su capacidad. En este caso el índice de desempeño potencial $P_{p}=0,86$, indica un proceso potencialmente no adecuado; de igual forma el índice de desempeño real Ppk $=0,19$ revela un proceso con pobre desempeño debido principalmente al descentrado de este. La diferencia más bien grande entre el Pp y el Ppk es un signo de que la distribución no está bien centrada entre los límites de especificación.

El nivel sigma de calidad, métrica utilizada para cuantificar el nivel de calidad de los procesos, permite concluir que para la humedad en el corto plazo es de 2,55 y en el largo plazo de 2,08, valores que se consideran no adecuados dado que son inferiores a 4 .

- Característica de calidad: Acidez (\%)

Para la Acidez se está ante una variable del tipo entre más pequeña mejor donde lo que interesa es que sean menores los valores a cierto valor máximo o $\mathrm{ES}$, que en este caso es $0,4 \%$.

La Figura N07 muestra que el proceso es capaz de cumplir con la ES, lo que se corrobora con el valor del índice de capacidad real del proceso, siendo superior a 1.25 que es el que se considera adecuado según Gutiérrez y De la Vara (2013) para procesos con solo una especificación. Los lotes que no cumplen con dicha especificación están en el orden de 71,84 por cada millón producido, lo que equivale a un nivel sigma de 3,8 cercano a 4, según se muestra en la Tabla №3.

\footnotetext{
"Visión de Futuro" Año 19, Volumen No 26 No 1, Enero - Junio 2022 - Pág 206 - 230

URL de la Revista: http://visiondefuturo.fce.unam.edu.ar/index.php/visiondefuturo/index

URL del Documento: https://visiondefuturo.fce.unam.edu.ar/index.php/visiondefuturo/issue/view/22

ISSN 1668 - 8708 - Versión en Línea

E-mail: revistacientifica@fce.unam.edu.ar
} 


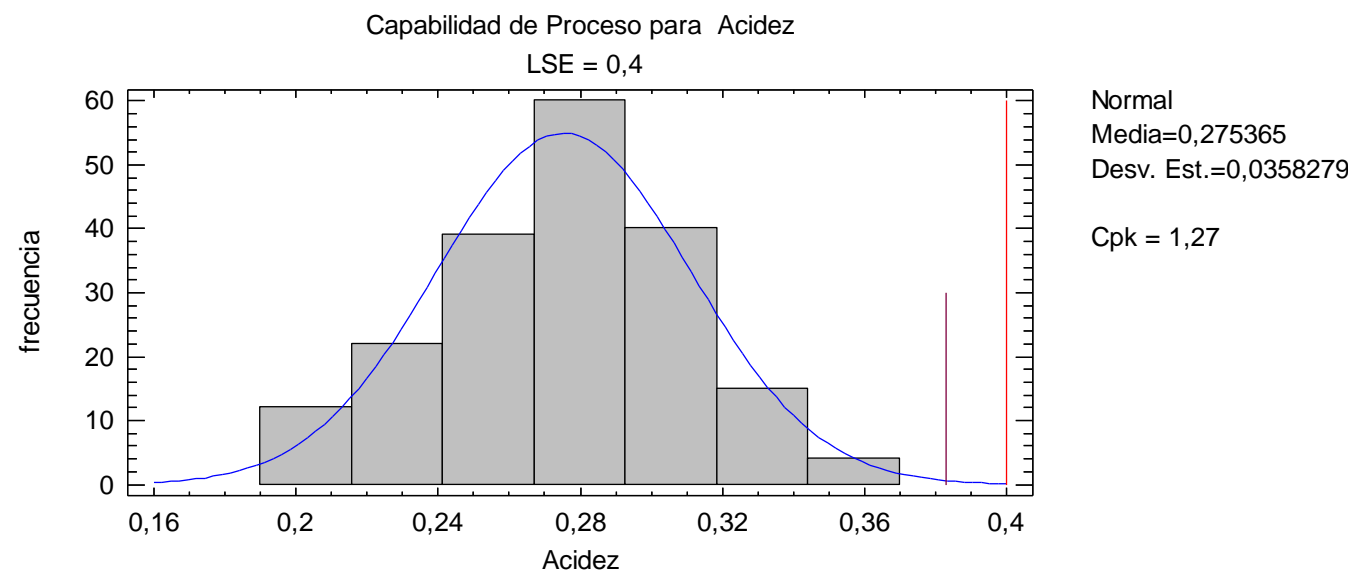

Figura N07: Análisis de capacidad para Acidez en el mes de abril de 2019 Fuente: Elaboración Propia

Tabla N³: Índices de capacidad para Acidez en el mes de abril de 2019

\begin{tabular}{|l|l|}
\hline \multicolumn{2}{|c|}{$\begin{array}{c}\text { Especificaciones } \\
\text { LSE }=0,4\end{array}$} \\
\hline Capacidad Corto Plazo & 0,032783 \\
\hline Sigma & 1,26727 \\
\hline Cpk (superior) & 0,00718448 \\
\hline$\%$ fuera de especificaciones & 71,8448 \\
\hline DPM & 3,8 \\
\hline Nivel Sigma & \multicolumn{2}{|c|}{} \\
\hline La sigma de corto plazo se estimó a partir del rango promedio. \\
\hline
\end{tabular}

Fuente: Elaboración Propia

\section{Análisis de normalidad}

Para que estos resultados sean válidos se requiere que la característica de calidad se distribuya en forma normal. Se realiza la prueba no paramétrica Chi-Cuadrado, cuyos resultados se muestran en la Tabla $N^{0} 4$ y Tabla $N^{0} 5$ para la humedad y la acidez respectivamente. Dado que el valor-P es mayor que 0,05 , no se puede rechazar la idea de que ambas características provienen de una distribución Normal con un 95\% de confianza.

Tabla NN 4: Prueba Bondad-de-Ajuste para Humedad. Prueba Chi-Cuadrada

\begin{tabular}{|l|l|l|l|l|l|}
\hline & Límite & Límite & Frecuencia & Frecuencia & \\
\hline & Inferior & Superior & Observada & Esperada & Chi-Cuadrada \\
\hline menor o igual & & 12,0 & 5 & 4,35 & 0,10 \\
\hline & 12,0 & 12,3333 & 23 & 20,07 & 0,43 \\
\hline & 12,3333 & 12,6667 & 43 & 50,57 & 1,13 \\
\hline & 12,6667 & 13,0 & 69 & 63,33 & 0,51 \\
\hline & 13,0 & 13,3333 & 34 & 39,45 & 0,75 \\
\hline & 13,3333 & 13,6667 & 17 & 12,21 & 1,88 \\
\hline mayor & 13,6667 & 1 & 2,02 & 0,51 \\
\hline \multicolumn{7}{|l|}{ Chi-Cuadrada $=5,31167$ con 4 g.l. Valor-P =0,256786 } \\
\hline
\end{tabular}

Fuente: Elaboración Propia

\footnotetext{
"Visión de Futuro" Año 19, Volumen N²6 N 1, Enero - Junio 2022 - Pág 206 - 230 URL de la Revista: http://visiondefuturo.fce.unam.edu.ar/index.php/visiondefuturo/index

URL del Documento: https://visiondefuturo.fce.unam.edu.ar/index.php/visiondefuturo/issue/view/22 
Tabla N5: Prueba Bondad-de-Ajuste para Acidez. Prueba Chi-Cuadrada

\begin{tabular}{|l|l|l|l|l|l|}
\hline & Límite & Límite & Frecuencia & Frecuencia & \\
\hline & Inferior & Superior & Observada & Esperada & Chi-Cuadrada \\
\hline menor o igual & & 0,21 & 12 & 6,54 & 4,57 \\
\hline & 0,21 & 0,23 & 19 & 13,19 & 2,56 \\
\hline & 0,23 & 0,25 & 22 & 26,26 & 0,69 \\
\hline & 0,25 & 0,27 & 33 & 38,59 & 0,81 \\
\hline & 0,27 & 0,29 & 47 & 41,87 & 0,63 \\
\hline & 0,29 & 0,31 & 40 & 33,53 & 1,25 \\
\hline & 0,31 & 0,33 & 5 & 19,82 & 11,08 \\
\hline mayor & 0,33 & 0,35 & 13 & 8,64 & 2,20 \\
\hline \multicolumn{6}{|l}{} \\
\hline
\end{tabular}

Fuente: Elaboración Propia

La Tabla N No6 muestra un resumen de los análisis realizados. Se evidencia que el proceso de producción de pastas largas para la característica de calidad humedad es inestable e incapaz de cumplir con especificaciones, mientras que para la Acidez se considera un proceso en control estadístico y capaz.

Tabla N6: Resumen del estado del proceso

\begin{tabular}{|c|c|c|c|}
\hline $\begin{array}{c}\text { Característica de } \\
\text { calidad }\end{array}$ & Estabilidad & Capacidad & $\begin{array}{c}\text { Métrica } \\
\text { Seis Sigma }\end{array}$ \\
\hline Humedad & Inestable & $\begin{array}{c}\text { Proceso incapaz de cumplir con la ES, al } \\
\text { estar descentrado un 77\% a la derecha del } \\
\text { valor nominal. }\end{array}$ & 2,55 \\
\hline Acidez & Estable & Capaz de cumplir con la ES & 3,80 \\
\hline
\end{tabular}

\section{Etapa III: Analizar}

Para investigar las posibles causas que inciden en la baja estabilidad y capacidad del proceso en cuanto a humedad se utilizó el diagrama causa-efecto. El mismo se construyó en una sesión de tormenta de ideas a partir de la experiencia acumulada de los trabajadores que laboran en el proceso. Las causas quedaron agrupadas en tres categorías: mano de obra, tecnología y métodos.

Para identificar las causas más probables se realizó un método de expertos con una escala del 1 al 5 donde 5 representa la causa más importante y 1 la menos importante. Participaron un total de ocho expertos. El planteamiento de la dócima es:

$\mathrm{H}_{0}$ : No hay acuerdo entre los expertos

$\mathrm{H}_{1}$ : Hay acuerdo entre los expertos

Los estadísticos de contraste de la prueba no paramétrica realizada muestran que la significación asintótica es de 0.000 , valor menor que 0.05 (nivel de significación estadística), por lo que se rechaza Ho, lo que se traduce en que existe comunidad de preferencia entre

\footnotetext{
"Visión de Futuro" Año 19, Volumen No 26 No 1, Enero - Junio 2022 - Pág 206 - 230

URL de la Revista: http://visiondefuturo.fce.unam.edu.ar/index.php/visiondefuturo/index

URL del Documento: https://visiondefuturo.fce.unam.edu.ar/index.php/visiondefuturo/issue/view/22

ISSN 1668 - 8708 - Versión en Línea

E-mail: revistacientifica@fce.unam.edu.ar
} 
los expertos con un coeficiente de concordancia W de Kendall de 0.977 . En la Tabla №7 se muestra el rango promedio para cada una de las causas analizadas, siendo las más críticas $Z_{3}, Z_{1}$ y $Z_{5}$.

Tabla N07: Método de expertos

\begin{tabular}{|c|l|c|}
\hline \multicolumn{2}{|c|}{ Causas } & Rango promedio \\
\hline$Z_{1}$ & $\begin{array}{l}\text { Deficiente capacitación de los operarios sobre los procedimientos y } \\
\text { normas a utilizar y las características de la materia prima. }\end{array}$ & 4,12 \\
\hline$Z_{2}$ & $\begin{array}{l}\text { Violaciones de las normas y procedimientos a utilizar. } \\
Z_{3}\end{array}$ & $\begin{array}{l}\text { Desconocimiento de los niveles de presión, temperatura y humedad } \\
\text { en las diversas fases del proceso que optimizan el por ciento de } \\
\text { humedad del producto final. }\end{array}$ \\
\hline$Z_{4}$ & Carencia de piezas de repuesto y accesorios. & 2,25 \\
\hline$Z_{5}$ & Falta de mantenimiento preventivo planificado. & 1,00 \\
\hline
\end{tabular}

Fuente: Elaboración Propia

\section{Etapa IV: Mejorar}

La etapa de mejora se enfocó en darle solución a la causa raíz principal $\left(Z_{3}\right)$, para la que se diseñó el plan de mejora correspondiente. La misma está en función de determinar los valores adecuados de las variables de control del proceso (Presión, temperatura y humedad) que permiten mejorar la estabilidad y capacidad para la característica de calidad objeto de análisis.

Se tomaron en cuenta 26 variables de control del proceso (X's) y una variable de respuesta correspondiente a la humedad del producto final $(\mathrm{Y})$. El estudio se inicia con un análisis de los estadísticos descriptivos de las variables a estudiar con el fin de eliminar datos erróneos. Se obtuvo una muestra total de 267 datos correspondiente a los meses de mayo a julio de 2019. Para cada variable se identifican errores de media bajos y coeficientes de variación que no superan el $15 \%$. La variable $X_{7}$ mantiene el mismo valor para cada caso, por lo que no es tomada en cuenta, dado que no brinda información importante en el análisis.

Se utilizaron técnicas multivariadas de reducción de datos (Análisis factorial), debido a la gran cantidad de variables que pudieran estar afectando la humedad del producto final. La técnica de componentes principales se aplicó con el fin de representar las 25 variables originales en nuevas variables (componentes principales) expresadas como combinación lineal de las originales. Se utilizó el criterio de autovalores mayores que 1 para la retención de componentes principales y se aplicó una rotación ortogonal Varimax.

Se retuvieron en total siete componentes principales, que explican el $68 \%$ de variabilidad total de los datos, lo que es adecuado. La prueba de esfericidad de Bartlett con una significación asintótica menor que 0,05 indica que existe relación entre las variables

\footnotetext{
“Visión de Futuro" Año 19, Volumen No 26 N 1, Enero - Junio 2022 - Pág 206 - 230

URL de la Revista: http://visiondefuturo.fce.unam.edu.ar/index.php/visiondefuturo/index

URL del Documento: https://visiondefuturo.fce.unam.edu.ar/index.php/visiondefuturo/issue/view/22

ISSN 1668 - 8708 - Versión en Línea

E-mail: revistacientifica@fce.unam.edu.ar
} 
independientes y la medida de adecuación muestral de Kaiser-Meyer-Olkin presenta un $\mathrm{KMO}>0,5$ por lo que existe adecuación de los datos a un análisis factorial.

Cada componente o nueva variable estará conformada por las combinaciones lineales de las variables originales que se muestran en la Tabla $N^{\circ} 8$. Es así como en el nuevo modelo la variable de respuesta se valoró en función de los siete componentes principales.

Tabla N8: Componentes principales

\begin{tabular}{|c|l|}
\hline $\begin{array}{c}\text { Nuevas variables } \\
\text { (Componente } \\
\text { principal) }\end{array}$ & \multicolumn{1}{c|}{ Descripción } \\
\hline $\mathrm{C}_{1}$ & $\begin{array}{l}\text { Se describe como combinación lineal de las variables: } \mathrm{x}_{14}, \mathrm{x}_{15}, \mathrm{x}_{16}, \mathrm{x}_{18}, \mathrm{x}_{21}, \\
\mathrm{x}_{22} \mathrm{y} \mathrm{x}_{24 .}\end{array}$ \\
\hline $\mathrm{C}_{2}$ & $\begin{array}{l}\text { Se describe como combinación lineal de las variables: } \mathrm{x}_{10}, \mathrm{x}_{11}, \mathrm{x}_{13}, \mathrm{x}_{17}, \mathrm{x}_{20}, \\
\mathrm{x}_{23} \mathrm{y} \mathrm{x}_{26} .\end{array}$ \\
\hline $\mathrm{C}_{3}$ & Se describe como combinación lineal de las variables: $\mathrm{x}_{3}$ y $\mathrm{x}_{25}$. \\
\hline $\mathrm{C}_{4}$ & Se describe como combinación lineal de las variables: $\mathrm{x}_{8}$ y $\mathrm{x}_{19}$. \\
\hline $\mathrm{C}_{5}$ & Se describe como combinación lineal de las variables: $\mathrm{x}_{1}, \mathrm{x}_{2} \mathrm{y} \mathrm{x}_{5}$. \\
\hline $\mathrm{C}_{6}$ & Se describe como combinación lineal de las variables: $\mathrm{x}_{6}$ y $\mathrm{x}_{9}$. \\
\hline $\mathrm{C}_{7}$ & Se describe como combinación lineal de las variables: $\mathrm{x}_{4} \mathrm{y} \mathrm{x}_{12}$. \\
\hline
\end{tabular}
Fuente: Elaboración Propia

Con el fin de determinar los valores óptimos de dichas variables se aplicó un modelo de superficies de respuesta correspondiente a un diseño experimental factorial $2^{7}$. Se pone de manifiesto que las variables 0 interacciones de ellas: $\mathrm{C}_{3}{ }^{*} \mathrm{C}_{7}, \mathrm{C}_{2}{ }^{*} \mathrm{C}_{3}$ y $\mathrm{C}_{6}$ repercuten significativamente en la variable de respuesta.

Una optimización del modelo para un valor ideal de humedad final del producto de $12 \%$ proporciona los valores óptimos de los componentes principales. Utilizando los modelos de superficies de respuesta para optimizar cada una de las variables originales a partir de cada variable componente principal se obtienen los valores óptimos que se muestran en la Tabla No9.

\footnotetext{
"Visión de Futuro" Año 19, Volumen No 26 N 1, Enero - Junio 2022 - Pág 206 - 230

URL de la Revista: http://visiondefuturo.fce.unam.edu.ar/index.php/visiondefuturo/index

URL del Documento: https://visiondefuturo.fce.unam.edu.ar/index.php/visiondefuturo/issue/view/22

ISSN 1668 - 8708 - Versión en Línea

E-mail: revistacientifica@fce.unam.edu.ar
} 
Tabla N 9: Valores óptimos para las variables originales

\begin{tabular}{|c|c|c|c|}
\hline Variables & Descripción & $\begin{array}{l}\text { Unidad de } \\
\text { medida }\end{array}$ & Valor óptimo \\
\hline $\mathrm{X} 1$ & Presión del cabezal & Bar & 137,407 \\
\hline $\mathrm{X} 2$ & Temperatura del agua de amasado & ${ }^{\circ} \mathrm{C}$ & 44,5228 \\
\hline $\mathrm{X} 3$ & Temperatura del cilindro & ${ }^{\circ} \mathrm{C}$ & 32,2854 \\
\hline X4 & Temperatura del cabezal & ${ }^{\circ} \mathrm{C}$ & 46,1463 \\
\hline $\mathrm{X} 5$ & Temperatura de ventilación del cabezal & ${ }^{\circ} \mathrm{C}$ & 63,3485 \\
\hline $\mathrm{X} 6$ & Temperatura de la central 1 de pre-secado & ${ }^{\circ} \mathrm{C}$ & 47,2116 \\
\hline $\mathrm{X} 7$ & Temperatura de la central 2 de pre-secado & ${ }^{\circ} \mathrm{C}$ & - \\
\hline $\mathrm{X} 8$ & Humedad de la central 2 de pre-secado & $\%$ & 65,3684 \\
\hline $\mathrm{X9}$ & Temperatura de la central 3 de pre-secado & ${ }^{\circ} \mathrm{C}$ & 71,1 \\
\hline $\mathrm{X} 10$ & Humedad de la central 3 de pre-secado & $\%$ & - \\
\hline $\mathrm{X} 11$ & Temperatura de la central 4 de pre-secado & ${ }^{\circ} \mathrm{C}$ & 68,0888 \\
\hline $\mathrm{X} 12$ & Humedad de la central 4 de pre-secado & $\%$ & 80,3823 \\
\hline $\mathrm{X} 13$ & Temperatura de la central 5 de pre-secado & ${ }^{\circ} \mathrm{C}$ & 72,7054 \\
\hline $\mathrm{X} 14$ & Temperatura de la central 6-7 de pre-secado & ${ }^{\circ} \mathrm{C}$ & 82,5744 \\
\hline $\mathrm{X} 15$ & Humedad de la central 6-7 de pre-secado & $\%$ & 54,2916 \\
\hline $\mathrm{X} 16$ & Temperatura de secado de la central 1 - 2 & ${ }^{\circ} \mathrm{C}$ & 66,9656 \\
\hline $\mathrm{X} 17$ & Humedad de secado de la central 1 - 2 & $\%$ & 58,3142 \\
\hline $\mathrm{X} 18$ & Temperatura de secado de la central 3 - 4 & ${ }^{\circ} \mathrm{C}$ & 79,0472 \\
\hline $\mathrm{X} 19$ & Temperatura de secado de la central $5-6$ & ${ }^{\circ} \mathrm{C}$ & 76,3454 \\
\hline $\mathrm{X} 20$ & Humedad de secado de la central 5 - 6 & $\%$ & 70,3196 \\
\hline $\mathrm{X} 21$ & Temperatura de secado de la central 7 - 8 & ${ }^{\circ} \mathrm{C}$ & 72,6413 \\
\hline $\mathrm{X} 22$ & Temperatura de secado de la central 9-10-11 & ${ }^{\circ} \mathrm{C}$ & 68,3651 \\
\hline $\mathrm{X} 23$ & Humedad de secado de la central 9-10-11 & $\%$ & 81,3846 \\
\hline $\mathrm{X} 24$ & Temperatura de secado de la central 12-13-14 & ${ }^{\circ} \mathrm{C}$ & 25,7837 \\
\hline $\mathrm{X} 25$ & Temperatura del enfriadero & ${ }^{\circ} \mathrm{C}$ & 28,8116 \\
\hline $\mathrm{X} 26$ & Presión de vacío & $\mathrm{mmHg}$ & $-617,847$ \\
\hline \multicolumn{4}{|c|}{$\begin{array}{l}\text { Nota: } \\
\mathrm{X}_{7} \text { : No incluida en el estudio. } \\
\mathrm{X}_{10} \text { : No se incorporó en la solución óptima porque presenta dependencias con el resto de } \\
\text { variables en el modelo de superficies de respuesta. }\end{array}$} \\
\hline
\end{tabular}

Fuente: Elaboración Propia

Orientado a la revisión de las medidas propuestas se diseñó un plan de control, según previo análisis en sesión de trabajo entre los integrantes del equipo.

\section{Etapa V: Controlar}

Una vez implantadas las acciones de mejora, es necesario verificar la efectividad de las mismas mediante el análisis de estabilidad y la evaluación de la habilidad del proceso para cumplir con especificaciones. Para efectuar el monitoreo se utilizaron nuevamente las cartas de medias y rangos y los índices de capacidad para variables con doble especificación. Los datos corresponden al mes de septiembre de 2019.

Se aprecia en ambas cartas de control (Ver Figura No8 y Figura No9) que no hay tendencias, ni ningún otro patrón especial, ni puntos fuera de los límites de control. Por tanto, el proceso ha estado funcionando de manera estable y se encuentra bajo control estadístico.

\footnotetext{
"Visión de Futuro" Año 19, Volumen No 26 No 1, Enero - Junio 2022 - Pág 206 - 230

URL de la Revista: http://visiondefuturo.fce.unam.edu.ar/index.php/visiondefuturo/index

URL del Documento: https://visiondefuturo.fce.unam.edu.ar/index.php/visiondefuturo/issue/view/22

ISSN 1668 - 8708 - Versión en Línea

E-mail: revistacientifica@fce.unam.edu.ar
} 
Gráfico X-bar para Humedad

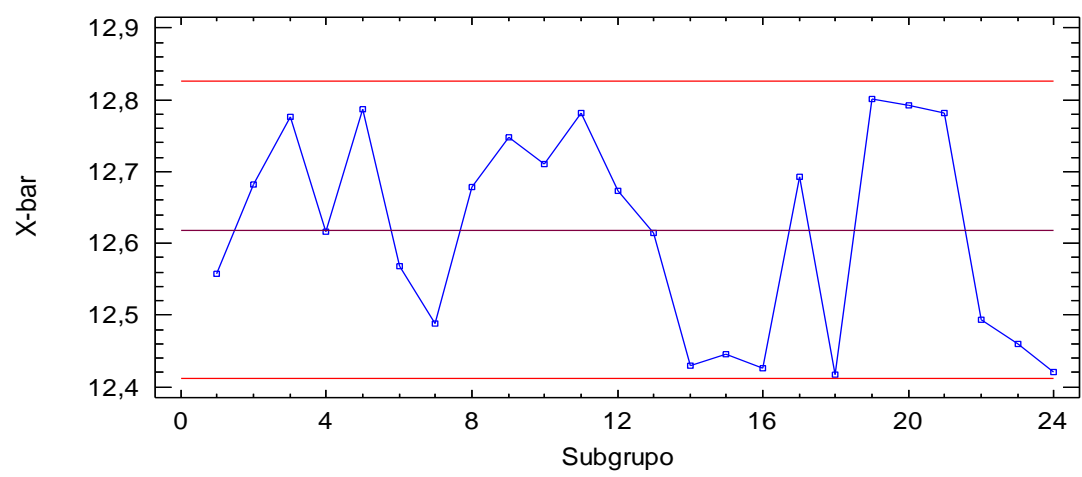

LSC $=12,83$

$\mathrm{CTR}=12,62$

$\mathrm{LIC}=12,41$

Figura N8: Gráfico de control de medias para la característica de calidad Humedad (\%) en el mes de septiembre de 2019

Fuente: Elaboración Propia

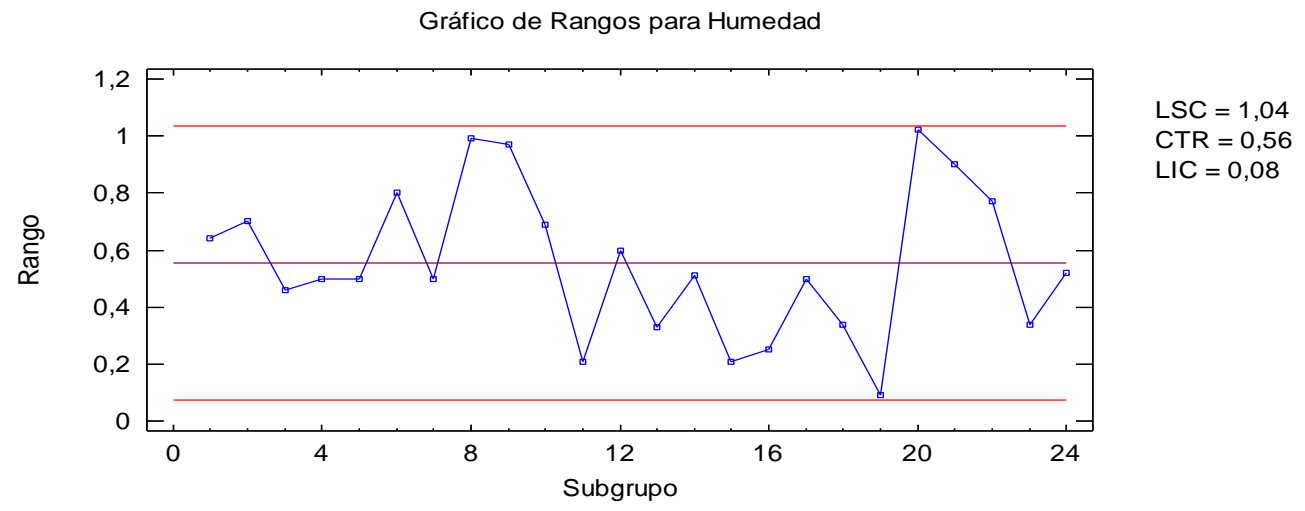

Figura N$^{\circ}$ 9: Gráfico de control de rangos para la característica de calidad Humedad (\%) en el mes de septiembre de 2019

Fuente: Elaboración Propia

El gráfico de capacidad se muestra en la Figura №10 y los valores estimados de los índices de capacidad en la Tabla №10. El proceso continúa siendo potencialmente capaz de cumplir con especificaciones con un valor de $C p=1,71$, adecuado para el trabajo según Gutiérrez y De la Vara (2013).

Se evidencia que el centrado del proceso mejoró, estando la media un $61,8 \%$ a la derecha del valor nominal según el índice $\mathrm{K}$, con una mejoría del $16 \%$ en relación al estado inicial. Lo anterior indica que todavía el descentrado del proceso influye en la baja capacidad de este, aunque en menor medida. El índice de capacidad real (Cpk) con valor de 0,65 y que coincide con el índice unilateral superior (Cpk superior) muestra un incremento, aunque aún insuficiente para considerarlo adecuado. De esta manera el $2,53 \%$ de los lotes contienen una humedad superior al 13\%, valor inferior al obtenido en el inicio de estudio que fue de 14,58\%. El proceso continúa siendo capaz de cumplir con la El al ser el índice Cpk (inferior) igual a 2,76 .

\footnotetext{
"Visión de Futuro" Año 19, Volumen No 26 N 1, Enero - Junio 2022 - Pág 206 - 230 URL de la Revista: http://visiondefuturo.fce.unam.edu.ar/index.php/visiondefuturo/index

URL del Documento: https://visiondefuturo.fce.unam.edu.ar/index.php/visiondefuturo/issue/view/22

ISSN 1668 - 8708 - Versión en Línea

E-mail: revistacientifica@fce.unam.edu.ar
} 
Tanto el índice de desempeño potencial $P_{p}$ y el índice de desempeño real Ppk experimentaron incrementos, lo que revela una mejoría en el desempeño del proceso. El número de sigmas de corto plazo también mejoró de 2,55 a 3,45, de igual forma el nivel de calidad de largo plazo cuyo valor varió de 2,08 a 2,97. No obstante continúan siendo inferiores a 4.

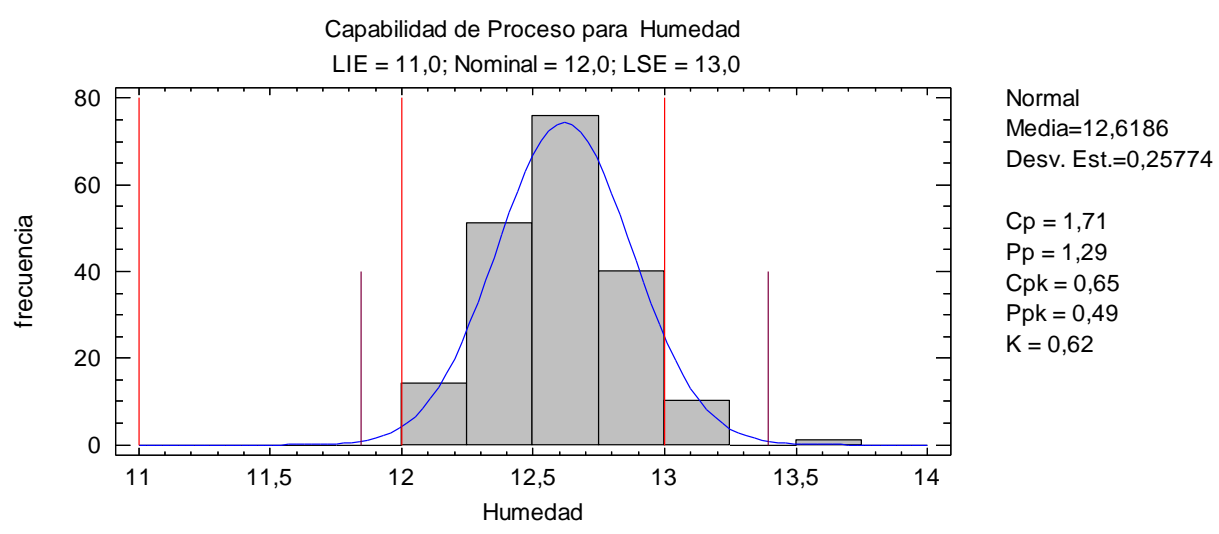

Figura № 10: Análisis de capacidad para Humedad en el mes de septiembre de 2019 Fuente: Elaboración Propia

Tabla № 10: Índices de capacidad para Humedad en el mes de septiembre de 2019

\begin{tabular}{|c|c|c|}
\hline \multicolumn{3}{|c|}{ Especificaciones } \\
\hline LSE $=13,0$ & Nom $=12,0$ & $\mathrm{LIE}=11,0$ \\
\hline Índices & $\begin{array}{l}\text { Capacidad } \\
\text { Corto Plazo }\end{array}$ & $\begin{array}{l}\text { Desempeño } \\
\text { Largo Plazo }\end{array}$ \\
\hline Sigma & 0,195235 & 0,25774 \\
\hline $\mathrm{Cp} / \mathrm{Pp}$ & 1,70735 & 1,29329 \\
\hline Cpk/Ppk & 0,651193 & 0,49327 \\
\hline Cpk/Ppk (superior) & 0,651193 & 0,49327 \\
\hline Cpk/Ppk (inferior) & 2,7635 & 2,09332 \\
\hline $\mathrm{K}$ & & 0,618594 \\
\hline$\%$ fuera de especificaciones & 2,53754 & 6,94618 \\
\hline DPM & 25375,4 & 69461,8 \\
\hline Nivel de Calidad Sigma & 3,45358 & 2,97981 \\
\hline
\end{tabular}

Fuente: Elaboración Propia

La comparación del estado del proceso antes y después de la mejora según se muestra en la Tabla №11 manifiesta que se pasa de un proceso Tipo D (Inestable Incapaz) a uno Tipo C (Estable e Incapaz) siguiendo el criterio de Gutiérrez y De la Vara (2013). Aunque este continúa siendo catalogado como incapaz de cumplir con especificaciones, se logra una mejoría que se manifiesta en el nivel de calidad sigma y el por ciento fuera de especificaciones.

\footnotetext{
"Visión de Futuro" Año 19, Volumen N²6 N 1, Enero - Junio 2022 - Pág 206 - 230

URL de la Revista: http://visiondefuturo.fce.unam.edu.ar/index.php/visiondefuturo/index

URL del Documento: https://visiondefuturo.fce.unam.edu.ar/index.php/visiondefuturo/issue/view/22

ISSN 1668 - 8708 - Versión en Línea

E-mail: revistacientifica@fce.unam.edu.ar
} 
Tabla $N^{\circ}$ 11: Resumen del estado del proceso antes y después de las mejoras

\begin{tabular}{|c|c|c|c|}
\hline Estabilidad & Capacidad & $\begin{array}{c}\text { Nivel de } \\
\text { calidad } \\
\text { sigma }\end{array}$ & $\begin{array}{l}\% \text { fuera de } \\
\text { especificaciones }\end{array}$ \\
\hline \multicolumn{4}{|c|}{ Estado inicial del proceso } \\
\hline Inestable & $\begin{array}{l}\text { - Proceso potencialmente capaz de cumplir con } \\
\text { especificaciones }(\mathrm{Cp}=1,55) \text {. } \\
\text { - Descentrado a la derecha, un } 77 \% \text { del valor } \\
\text { nominal }(\mathrm{K}=0,77) \text {. } \\
\text { - Proceso incapaz de cumplir con la ES (Cpk=Cpk } \\
\text { superior }=0,35) \text {. }\end{array}$ & 2,55 & $14,58 \%$ \\
\hline \multicolumn{4}{|c|}{$\begin{array}{l}\text { Proceso tipo D: Inestable e Incapaz según el criterio de Gutiérrez y De la Vara (2013) } \\
\text { Un proceso muy inestable se caracteriza por estar pobremente estandarizado. }\end{array}$} \\
\hline \multicolumn{4}{|c|}{ Estado final del proceso } \\
\hline Estable & $\begin{array}{l}\text { - Proceso potencialmente capaz de cumplir con } \\
\text { especificaciones }(\mathrm{Cp}=1,70) \text {. } \\
\text { - Descentrado a la derecha, un } 61 \% \text { del valor } \\
\text { nominal }(\mathrm{K}=0,61) \text {. } \\
\text { - Proceso incapaz de cumplir con la ES (Cpk=Cpk } \\
\text { superior }=0,65)\end{array}$ & 3,45 & $2,53 \%$ \\
\hline \multicolumn{4}{|c|}{$\begin{array}{l}\text { Proceso tipo C: Estable e Incapaz según el criterio de Gutiérrez y De la Vara (2013) } \\
\text { Se está ante un proceso establemente malo. }\end{array}$} \\
\hline
\end{tabular}

Fuente: Elaboración Propia

El gráfico de probabilidad normal que se muestra en la Figura $N^{0} 11$ evidencia el cumplimiento del supuesto de normalidad de los datos, dado que los puntos caen cerca de la línea recta.

Gráfico de Probabilidad

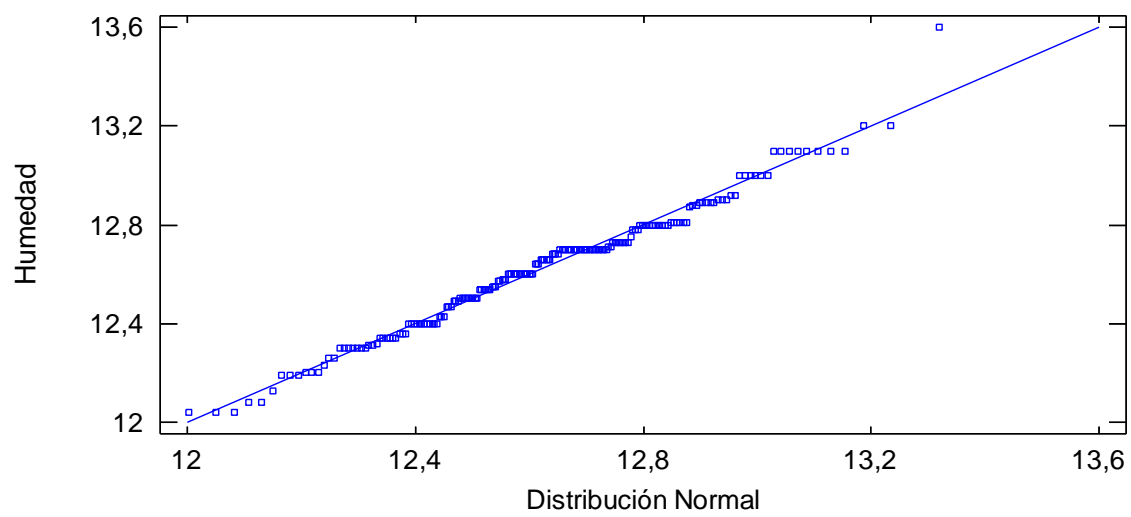

Media $=12,6186$

Desv. Est. $=0,25774$

Figura No 11: Gráfico de probabilidad normal para Humedad en el mes de septiembre de 2019 Fuente: Elaboración Propia

\section{CONCLUSIONES}

1. La implementación de metodologías como seis sigma unido al uso de herramientas y técnicas del control estadístico de la calidad en el sector alimentario, contribuyen al cumplimiento de las normas alimentarias establecidas y al control de los procesos de producción para garantizar la calidad e inocuidad de estos.

\footnotetext{
“Visión de Futuro" Año 19, Volumen No 26 N 1, Enero - Junio 2022 - Pág 206 - 230

URL de la Revista: http://visiondefuturo.fce.unam.edu.ar/index.php/visiondefuturo/index

URL del Documento: https://visiondefuturo.fce.unam.edu.ar/index.php/visiondefuturo/issue/view/22

ISSN 1668 - 8708 - Versión en Línea

E-mail: revistacientifica@fce.unam.edu.ar
} 
2. Las pérdidas por mala calidad del producto de la empresa de pastas largas objeto de estudio ascienden a 66,60 toneladas, equivalente a 95160 pesos en el período enero-abril de 2019 , donde el espaguetis grado B representa el $84,94 \%$ del monto total.

3. El análisis de estabilidad y capacidad de las variables físico-químicas evidencia que el proceso de producción de pastas largas es inestable e incapaz de cumplir con especificaciones para la característica de calidad "Humedad". El principal problema se debe al descentrado del proceso, con un $77 \%$ a la derecha del valor nominal, lo que influye en su baja capacidad, para un nivel de calidad sigma de 2,55. En este sentido el $14,58 \%$ de los lotes producidos poseen una humedad superior al $13 \%$.

4. Para el desarrollo de la propuesta de mejora se utilizaron técnicas multivariadas de reducción de datos (Análisis factorial) y el diseño de experimentos, lo que permitió determinar los valores óptimos de 24 variables de control del proceso para un valor ideal de humedad del producto final de $12 \%$. La efectividad de la propuesta se manifestó en una mejoría en el centrado del proceso con una disminución del índice $\mathrm{K}$ de $16 \%$ en relación al estado inicial, para un 2,53\% fuera de especificaciones y un nivel de calidad sigma de 3,45.

5. Los resultados obtenidos permitieron alcanzar un proceso estable y en control estadístico, siendo potencialmente capaz de cumplir con especificaciones. Mejoró el centrado, así como su desempeño potencial y real, cuyos índices experimentaron incrementos. Se pasó de un proceso Tipo D (Inestable e Incapaz) a uno Tipo C (Estable e Incapaz), así como se manifestó una mejoría en el nivel de calidad sigma y el por ciento fuera de especificaciones.

\section{REFERENCIAS}

Abdul, S., Antony, J., y Arshed, N. (2016). A critical assessment on SPC implementation in the UK Food Industry. Systemics, Cybernatics and Informatics, 14(1), 37-42. [Fecha de Consulta 20 de Enero de 2021]. ISSN: 1690-4524. Disponible en: http://www.iiisci.org/journal/CV\$/sci/pdfs/SA430BZ15.pdf

Abdul, S., Antony, J., Arshed, N., y Albliwi, S. (2017). A systematic review of statistical process control implementation in the food manufacturing industry. Total Quality Management \& Business Excellence, 28(1-2), 176189. https://doi.org/10.1080/14783363.2015.1050181

Biernacka, B., Dziki, D., Gawlik-Dziki, U., Różyło, R., y Siastała, M. (2017). Physical, sensorial, and antioxidant properties of common wheat pasta enriched with carob

\footnotetext{
"Visión de Futuro" Año 19, Volumen No 26 N 1, Enero - Junio 2022 - Pág 206 - 230

URL de la Revista: http://visiondefuturo.fce.unam.edu.ar/index.php/visiondefuturo/index

URL del Documento: https://visiondefuturo.fce.unam.edu.ar/index.php/visiondefuturo/issue/view/22

ISSN 1668 - 8708 - Versión en Línea

E-mail: revistacientifica@fce.unam.edu.ar
} 
fiber. LWT - Food Science and Technology, 77, 186-

192. https://doi.org/10.1016/j.lwt.2016.11.042

Biernacka, B., Dziki, D., Różyło, R., Wójcik, M., Miś, A., Romankiewicz, D., y Krzysiak, Z. (2018). Relationship between the properties of raw and cooked spaghetti - new indices for pasta quality evaluation. International Agrophysics, 32(2), 217223. http://dx.doi.org/10.1515/intag-2017-0012

Bouasla, A., Wójtowicz, A., y Zidoune, M. N. (2017). Gluten-free precooked rice pasta enriched with legumes flours: Physical properties, texture, sensory attributes and microstructure. LWT - Food Science and Technology, 75, 569577. https://doi.org/10.1016/j.lwt.2016.10.005

Bustos, M. C., Pérez, G. T., y León, A. E. (2015). Structure and quality of pasta enriched with functional ingredients. RSC

Advances, 5(39),

3078030792. https://doi.org/10.1039/C4RA11857J

Carrasquero, P. J. (2009). Evaluación de calidad de las pastas alimenticias de sémola durum. (tesis de maestría). Universidad del Zulia, Estado de Zulia, Venezuela.

Chero, P. A. (2019). Statistical process control applied in the chemical and food industry. Journal of Material Sciences \& Engineering, 8(4), 1-7. [Fecha de Consulta 20 de Enero de 2021]. ISSN: 2169-0022. Disponible en: https://www.hilarispublisher.com/open-access/statistical-process-control-applied-in-thechemical-and-food-industry.pdf

Fuad, T., y Prabhasankar, P. (2010). Role of ingredients in pasta product quality: A review on recent developments. Critical Reviews in Food Science and Nutrition, 50(8), 787798. http://dx.doi.org/10.1080/10408390903001693

García, Y. (2014). Aplicación de la Metodología Seis Sigma para el mejoramiento de la calidad de las reparaciones, en la Agencia SASA Villa Clara. (tesis de maestría). Universidad Central de las Villas, Santa Clara, Cuba.

Garsa, A. S. (2017). Preparation and quality evaluation of pasta substituted with hull-less barley. Australian Journal of Basic and Applied Sciences, 11(1), 98-106. [Fecha de Consulta 20 de Enero de 2021]. ISSN: 2309-8414. Disponible en: http://www.ajbasweb.com/old/ajbas/2017/January/98-106.pdf

Gutiérrez, H., y De la Vara, R. (2013). Control estadístico de la calidad y Seis Sigma. (3ra ed.). México: Editorial McGraw-Hill.

Idrissi, I., y Benazzouz, B. (2019). Lean or Six Sigma for food industry? Perspectives from previous researches and case studies in industry. International Journal of Civil Engineering and Technology, 10(4), 1732-1739. [Fecha de Consulta 20 de Enero de 
2021]. ISSN: 0976-6316. Disponible en:

http://www.iaeme.com/ijciet/issues.asp?JType=IJCIET\&VType=10\&IType=04

ISO 13053: 2011. Quantitative methods in process improvement, Six Sigma. Ginebra, Suiza. Larrosa, V., Lorenzo, G., Zaritzky, N., y Califano, A. (2016). Improvement of the texture and quality of cooked gluten-free pasta. LWT - Food Science and Technology, 70, 96103. https://doi.org/10.1016/j.lwt.2016.02.039

Makhlouf, S., Jones, S., Hong, S., Sancho, M., Burns, B., y Olive, Y. (2019). Effect of selected dietary fibre sources and addition levels on physical and cooking quality attributes of fibre-enhanced pasta. Food Quality and Safety, 3(2), 117127. https://doi.org/10.1093/fqsafe/fyz010

Message, L. B., Godhino, M., Fredendall, L. D., y Gómez, F. J. (2018). Lean, six sigma and lean six sigma in the food industry: A systematic literature review. Trends in Food Science \& Technology, 82, 122-133. https://doi.org/10.1016/j.tifs.2018.10.002

Murray, J. C., Kiszonas, A., y Morris, C. F. (2017). Pasta production: Complexity in defining processing conditions for reference trials and quality assessment methods. Cereal Chemistry, 94(5), 791-797. https://doi.org/10.1094/CCHEM-04-17-0072-RW

NC 935: 2012. Pastas alimenticias secas-Especificaciones. La Habana, Cuba.

NRIAL 168: 2001. Pastas alimenticias. Especificaciones. La Habana, Cuba

Ogawa, T., y Adachi, S. (2017). Drying and rehydration of pasta. Drying Technology, 35(16), 1919-1949. https://doi.org/10.1080/07373937.2017.1307220

Peña, A. (2019). Estandarización de método alternativo para la determinación de humedad en pastas alimenticias secas. (tesis de grado). Universidad Nacional Abierta y a Distancia, Bogotá, Colombia.

Piwińska, M., Wyrwisz, J., Kurek, M. A., y Wierzbicka, A. (2016). Effect of drying methods on the physical properties of durum wheat pasta. CyTA - Journal of Food, 14(4), 523528. http://dx.doi.org/10.1080/19476337.2016.1149226

Rábago, D. M., Padilla, E., y Rangel, J. G. (2014). Statistical quality control and process capability analysis for variability reduction of the tomato paste filling process. Industrial Engineering \& Management, 3(4), 1-7. https://doi.org/10.4172/2169-0316.1000137

Ramírez, A. M. (2015). Evaluación de características físicas, químicas y sensoriales de pasta Fettuccine con sustitución parcial de harina de trigo por almidón de yuca y cáscara de huevo. (tesis de grado). Escuela Agrícola Panamericana, ciudad, país.

Sicignano, A., Di Monaco, R., Masi, P., y Cavella, S. (2015). From raw material to dish: Pasta quality step by step. Journal of the Science of Food and Agriculture, 95(13), 2579-2587. https://doi.org/10.1002/jsfa.7176 
Soriano, F., Oprime, P. C., y Lizarelli, F. L. (2017). Impact analysis of critical success factors on the benefits from statistical process control implementation. Production, 27, 113. https://doi.org/10.1590/0103-6513.204016

\section{RESUMEN BIOGRÁFICO}

\section{Roxana González Alvarez}

Máster en Ciencias en Ingeniería Industrial (Mención Calidad). Profesora Auxiliar del Departamento de Ingeniería Industrial de la Facultad de Ingeniería de la Universidad de Cienfuegos. Áreas de experiencia: Ingeniería de Calidad, Gestión de Calidad y Calidad de los Servicios.

\section{Aníbal Barrera García}

Máster en Ciencias en Matemática Aplicada, Máster en Ciencias en Ingeniería Industrial (Mención Calidad). Profesor Auxiliar del Departamento de Ingeniería Industrial de la Facultad de Ingeniería de la Universidad de Cienfuegos. Áreas de experiencia: Metrología, Ingeniería de Calidad, Gestión de Calidad y Sistemas Integrados de Gestión.

\section{Ana Beatriz Guerra Morffi}

Estudiante de la Carrera de Ingeniería Industrial de la Facultad de Ingeniería de la Universidad de Cienfuegos.

\section{Juan Felipe Medina Mendieta}

Máster en Nuevas Tecnologías para la Educación. Profesor Auxiliar del Departamento de Matemática de la Facultad de Ciencias Económicas y Empresariales de la Universidad de Cienfuegos. Áreas de experiencia: Nuevas Tecnologías para la Educación, Estadística y Matemática Aplicada.

\footnotetext{
“Visión de Futuro" Año 19, Volumen No 26 N 1, Enero - Junio 2022 - Pág 206 - 230 